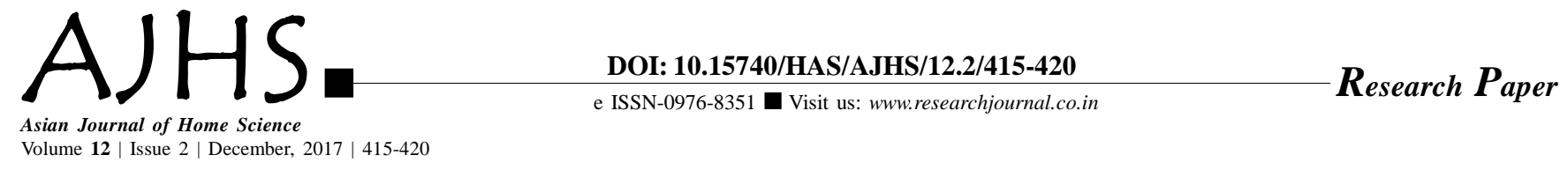

\title{
A comparative study of machine knitted cotton fabrics
}

\author{
RENU SINGH AND RITU PANDEY
}

Received: 01.05.2017; Revised: 30.09.2017; Accepted: 16.10.2017

See end of the paper for authors' affiliations RENU SINGH

Department of Home Science, University of Allahabad, ALLAHABAD (U.P.) INDIA
ABSTRACT : A comparative study of three types of machine knitted cotton fabrics viz., plain, rib and tuck was carried out in order to find out the most serviceable knit stitch. The present study moves around the raw material and knit stitches used for the knitting of the samples. All the knitted fabrics were produced by using cotton yarn. The machine parameters were also kept constant for the manufacturing of all the three types of fabrics. The experimental research design was used for conducting present investigation. The performance study of the fabric was done on the basis of physical tests related to durability, strength, maintenance, aesthetic appearance etc. The results reveal that variable (three knit stitches) had significant effect on the performance of the fabrics. It was observed from the study that plain knit stitch was the best serviceable knit stitch among the stitches.

KEY WORDS: Knit stitch, Plain stitch, Rib stitch, Tucks stitch, Serviceability, Physical properties, Cotton yarn, Machine knitting, Durability, Maintenance

- HOW TO CITE THIS PAPER : Singh, Renu and Pandey, Ritu (2017). A comparative study of machine knitted cotton fabrics. Asian J. Home Sci., 12 (2) : 415-420, DOI: 10.15740/HAS/AJHS/12.2/415-420. 